\title{
Uso e conhecimento ortográfico no transtorno específico da leitura
}

\section{Orthographic knowledge and use in children with dyslexia}

\author{
Rosana Siqueira Dias', Clara Regina Brandão de Ávila²
}

\begin{abstract}
RESUMO
Objetivo: Investigar como escolares com Transtorno Específico de Leitura (TLE) aplicam em suas escritas a regra de correspondência fono-grafêmica independente do contexto e como identificam e analisam os erros que produzem na escrita, segundo as variáveis: frequiência de aparecimento do item lingüístico e a série do escolar. Métodos: Foram analisados e comparados os erros de escrita obtida a partir de ditado de palavras de alta e baixa freqüência e pseudopalavras, de escolares de $1^{\text {a }}$ a $4^{\text {a }}$ série da rede particular de ensino fundamental. Avaliaram-se 56 escolares: 28 com TLE constituíram o grupo pesquisa e 28 sem queixas ou alterações, pareados por idade, sexo e série, o grupo de comparação. Justificativas dos erros e acertos de escrita foram gravadas e comparadas. Resultados: Os escolares do grupo pesquisa mostraram pior desempenho quando comparados com o de comparação. Além disso, observou-se diminuição dos erros, conforme a progressão da escolaridade, principalmente na escrita de palavras de alta frequiência. Os escolares do grupo pesquisa apresentaram maior dificuldade em analisar os itens lingüísticos escritos e reconhecer as escritas corretas. Conclusões: As crianças com transtorno específico de leitura apresentaram maior dificuldade em escrever e analisar a escrita de ortografia transparente. O efeito da freqüência do item lingüístico facilitou a identificação do erro. Nesse grupo de escolares os erros diminuíram com a progressão das séries e variaram conforme o item lingüístico.
\end{abstract}

Descritores: Dislexia; Escrita manual; Avaliação; Linguagem infantil; Aprendizagem

\section{INTRODUÇÃO}

Atualmente, verifica-se uma constante preocupação, com relação às dificuldades do aprendizado da leitura e da escrita, no âmbito científico da saúde e da educação. Entretanto, a maioria das pesquisas ainda focaliza, principalmente, a avaliação da leitura.

Há um número menor de estudos em que se pode observar a preocupação em avaliar o conhecimento que os escolares possuem sobre as regras ortográficas e seus usos. Grande parte destas pesquisas está relacionada com o aprendizado geral da ortografia e se limita a verificar o desempenho na escrita, ou seja, a analisar os erros que aparecem na escrita de crianças com e sem dificuldades escolares, com o objetivo de descrever a forma como elas aprendem a dominar as regras ortográficas. Contudo, ainda, não se sabe como os escolares representam as propriedades da norma ortográfica e não se esclareceu, ainda, o que leva o aluno a corrigir seus erros e passar destes para o acerto $^{(1)}$.

Trabalho realizado no Departamento de Fonoaudiologia da Universidade Federal de São Paulo - UNIFESP - São Paulo (SP), Brasil.

(1) Mestre em Ciências dos Distúrbios da Comunicação Humana pela Universidade Federal de São Paulo - UNIFESP - São Paulo (SP), Brasil; Fonoaudióloga clínica.

(2) Doutora, Professora do Departamento de Fonoaudiologia da Universidade Federal de São Paulo - UNIFESP - São Paulo (SP), Brasil.

Endereço para correspondência: Rosana Siqueira Dias. R. São Roque, 51, Bela Vista, Caconde-SP, CEP 13770-000.E-mail: ro.dias@itelefonica.com.br Recebido em: 26/9/2007; Aceito em: 30/9/2008
Estudos experimentais sobre a aquisição da leitura e da escrita no Português Brasileiro afloraram a partir da década de 80 e, de maneira geral, essas pesquisas avaliaram o desempenho em ortografia $a^{(2-12)}$.

O aprendizado da escrita pressupõe a compreensão de uma série de propriedades ou aspectos da língua escrita que fazem parte do sistema ortográfico. Esse aprendizado engloba: diferenciar o traçado das letras, saber a que sons as letras correspondem, estabelecer correspondências quantitativas, identificar a posição da letra dentro da palavra, compreender que uma mesma letra pode representar vários sons, assim como um mesmo som pode ser representado por diversas letras.

Portanto, escrever ortograficamente não é tarefa fácil. Nos primeiros estágios do aprendizado ortográfico, a criança precisa entender que é possível analisar os sons de uma palavra falada e escrevê-los usando um conjunto de letras que ela também precisa aprender. Assim, é possível pressupor que a compreensão do princípio alfabético necessita de três fatores facilitadores: a capacidade de segmentar a língua falada em unidades distintas; a consciência de que essas unidades repetem-se em diferentes palavras faladas e o conhecimento das regras de correspondência entre grafemas e fonemas ${ }^{(4,7)}$. O desenvolvimento da habilidade para lidar com as palavras no sentido de segmentá-las em sílabas e fonemas tem sido apontado como um aspecto crucial para se entender a aquisição da leitura e da escrita, assim como suas dificuldades ${ }^{(13-16)}$. A estreita relação entre o domínio da escrita alfabética e a consciência fonológica é, portanto, conhecida e estudada há 
algum tempo ${ }^{(3,13-14,16-19)}$. Entretanto, a capacidade de segmentar as palavras em fonemas parece não ser a única competência metalingüística, necessária para o aprendizado ortográfico.

O domínio do código gráfico também se expressa pela apropriação de outras regras de ortografia, não somente a que contempla a correspondência direta entre fonemas e grafemas, independentemente do contexto. E até que o domínio seja alcançado, em seu percurso acadêmico, os alunos apresentam erros de diferentes naturezas e com diferentes frequiências até chegarem ao ponto de escreverem corretamente ${ }^{(6)}$.

Sabe-se, também que os sistemas de escrita não se atêm somente às suas bases fonológicas e que o aprendiz necessita de outras habilidades para chegar à etapa da escrita ortográfica. O domínio das regras ortográficas parece depender de conhecimentos diferentes sobre os diversos elementos da língua ${ }^{(6,12,20-21)}$.

De fato, já em $1997^{(3)}$ investigaram-se as relações entre o desenvolvimento da consciência metalingüística, em especial, o da consciência sintática e o aprendizado de regras ortográficas, em escolares brasileiros de classe médio-baixa de primeira e segunda série do Ensino Fundamental. Esse estudo concluiu que a consciência sintática é um facilitador específico da aquisição de regras ortográficas que envolvem análises morfossintáticas por serem dependentes do contexto da escrita, enquanto a consciência fonológica contribui, principalmente, para a aquisição de regras de contexto grafofônico. Estudos recentes $^{(10-11)}$ comprovaram estes achados.

Então, o aprendizado da escrita ortográfica envolve processos metacognitivos, de análise dos fatos da grafia, ou metagráfica, que a criança faz até dominar o uso das regras. Estas competências devem conferir ao aprendiz a capacidade de explicar o porquê da forma de escrever uma ou outra palavra.

Pesquisas têm evidenciado que escolares com transtorno específico da leitura (TEL) estabelecem conexões rudimentares entre os fonemas, as palavras faladas e as sequiências de letras impressas ${ }^{(9,21-22)}$. Outras têm mostrado que principalmente em tarefas metacognitivas de consciência fonológica este grupo de escolares apresenta dificuldades e falhas em seu desempenho $^{(8,17,19,23-24)}$.

Esta pesquisa focalizou a atenção em crianças com TEL, considerando o desempenho da leitura e da escrita, que, medidos por testes padronizados, mostraram-se abaixo do nível esperado para a idade cronológica, a inteligência medida e a escolaridade, apropriada à idade do indivíduo ${ }^{(25)}$. Nestes quadros, geralmente, o escolar falha em atividades de leitura e, também, da escrita, devido a alterações do processamento de informações fonológicas ${ }^{(6,17,22,24)}$. Entretanto, mesmo na presença destas alterações (que acontecem na ausência de qualquer prejuízo intelectual, sensorial, perceptivo, social ou educacional), o escolar com TEL desenvolve de alguma forma e em algum grau, suas capacidades de aprendizado e de lidar com o sistema alfabético. Aprende a ler e a escrever, utilizando caminhos de processamento de informação diferentes daqueles esperados. A maneira como esse modo de aprender influencia as atividades de leitura e de escrita, ainda é objeto de estudo.

O conhecimento sobre o modo como utiliza regras orto- gráficas para escrever, ainda, foi pouco explorado. Um estudo sobre o desenvolvimento da ortografia em crianças tchecas ${ }^{(22)}$ sugeriu que, nos escolares com TEL há um prejuízo persistente na representação ortográfica da estrutura fonológica de palavras, na escrita. Mostrou também que crianças disléxicas tchecas, com 11 anos, apesar de já cursarem a $5^{a}$ série, continuam a produzir altos índices de erros ortográficos relacionados à imprecisão fonológica. Outra pesquisa ${ }^{(26)}$ relatou que até mesmo universitários podem apresentar dificuldades na produção escrita que envolve o domínio de certas regras ortográficas.

Provavelmente, o processo de conversão fonológicoortográfica, isoladamente, seja insuficiente para a obtenção da correta ortografia de palavras. Assim, os erros podem indicar a presença de déficits no processamento ortográfico ${ }^{(9)}$.

Certamente, as características psicolingüísticas das palavras interferem no aprendizado e desempenho ortográficos. Em 1994, um estudo referiu que as palavras de alta freqüência foram escritas com mais correção do que as palavras inventadas tanto por crianças com dificuldades quanto sem dificuldades ortográficas. Todas acertaram menos ao escrever pseudopalavras do que palavras ${ }^{(2)}$. Sabe-se que ao apreender o sistema de escrita, a criança faz dois aprendizados: domina o princípio do sistema alfabético (no que depende da capacidade de associação fonema-grafema) e o da norma ortográfica com suas regularidades e irregularidades (subordinada a análises metagráficas e conhecimentos sintáticos, mais ou menos explícitos). Sabe-se, também que a escrita de transparência ortográfica pode ser caracterizada pela correspondência direta entre o fonema e o grafema, independentemente das regras de contexto. Portanto, a análise dessa escrita poderia fornecer importantes informações sobre a real capacidade da criança em associar a letra ao som correspondente. Estas informações, analisadas separadamente daquelas que se referem ao uso de outras regras ortográficas, podem ser úteis para a compreensão do aprendizado da leitura e da escrita e de seus transtornos ${ }^{(9,22)}$. Inúmeras vezes, por meio da avaliação da escrita de escolares com queixas de leitura e de escrita observam-se diversos erros cuja classificação, nem sempre atende às necessidades do clínico, na edificação de seu plano de remediação. Deve-se compreender que a avaliação da leitura e da escrita são processos integrados e complexos de construção, tendo sempre em mente a avaliação para a aprendizagem. Além disso, para avaliar a ortografia é importante recordar o caráter evolutivo de seu aprendizado para facilitar as estratégias de ensino e reabilitação, posteriormente. A habilidade da criança de gerar suas próprias idéias deve ser valorizada, estimulando a autonomia e a formulação de opiniões, mesmo durante o processo de avaliação ${ }^{(27)}$.

A caracterização da escrita de palavras de ortografia transparente avalia isoladamente, o uso e o conhecimento da regra de correspondência fonema-grafema direta e independente do contexto $^{(28)}$. Esta, ligada ao princípio de codificação escrita, no Português, parece ser a de maior complexidade para o domínio da alfabetização uma vez que depende exclusivamente da aprendizagem da criança ${ }^{(28)}$. Daí a importância de avaliar isoladamente o conhecimento e aplicação dessa regra na escrita. Diferenciar e caracterizar os desempenhos de escolares com TEL comparando-os com os de escolares típicos ou sem 
queixa de leitura e escrita, ao escreverem itens ortograficamente transparentes pode fornecer ferramentas importantes para a abordagem clínica com essas crianças.

Assim, este estudo teve como objetivo investigar como escolares com TLE aplicam em suas escritas a regra de correspondência fono-grafêmica independente do contexto, caracterizar seus desempenhos e avaliar como identificam e analisam os erros que produzem na escrita, levando em consideração as variáveis frequiência de aparecimento do item lingüístico e a série do escolar.

\section{MÉTODOS}

Este trabalho recebeu aprovação do Comitê de Ética e Pesquisa da Universidade Federal de São Paulo (UNIFESP), sob o $\mathrm{n}^{\circ} 1155 / 04$.

Inicialmente, as instituições em que a pesquisa foi realizada assinaram o termo de autorização. A seguir, os pais dos escolares que participaram da pesquisa também assinaram o termo de consentimento livre e esclarecido, permitindo, inclusive, a divulgação dos resultados.

\section{Seleção da amostra}

Foram selecionados 56 escolares de $1^{\mathrm{a}}$ a $4^{\mathrm{a}}$ série, do sexo masculino e feminino, na faixa etária entre sete e dez anos de idade, todos os alunos regularmente matriculados em Escolas da Rede Particular de Ensino Fundamental do Município de São Paulo-SP.

Os escolares constituíram dois grupos:

\section{Grupo Pesquisa (GP)}

Constituído por 28 escolares (17 meninos) do Ensino Fundamental. Cinco dos escolares eram estudantes da $1^{\mathrm{a}}$ série, 12 da $2^{\mathrm{a}}$ série, 5 da $3^{\mathrm{a}}$ série e 6 da $4^{\mathrm{a}}$ série, de diversas escolas da rede particular de ensino, de diferentes regiões do município de São Paulo - SP.

Todos apresentavam à época da avaliação, diagnóstico multidisciplinar de Transtorno Específico da Leitura, obtido em Instituição Brasileira que tem por objetivo atender e orientar pessoas com distúrbios de aprendizagem, mais especificamente, quanto ao Transtorno Específico da Leitura. Esse grupo foi, portanto, composto por escolares que apresentavam comprometimento específico e significativo do desenvolvimento das habilidades da leitura, não atribuível exclusivamente à idade mental, a transtornos de acuidade visual ou escolarização inadequada, com possível comprometimento da capacidade de compreensão da leitura, reconhecimento das palavras, leitura oral, e desempenho de tarefas que necessitam da leitura. Os casos avaliados também apresentavam dificuldades de soletração e alterações de escrita ${ }^{(25)}$.

O diagnóstico obtido e fornecido por esta instituição é multidisciplinar e de exclusão. Foram excluídos da amostra desta pesquisa, escolares com déficit intelectual, disfunções ou deficiências auditivas e visuais, lesões cerebrais (congênitas e adquiridas), desordens afetivas anteriores ao processo do fracasso escolar, déficit de atenção e hiperatividade.

Admitiu-se na constituição deste grupo, escolares que freqüentavam terapia fonoaudiológica há, no máximo seis meses, mas que, ainda, apresentavam a queixa relacionada ao transtorno de leitura e escrita.

\section{Grupo de Comparação $(G C)$}

Constituído por 28 escolares (17 meninos) pareados aos do GP, por sexo, faixa etária e série escolar. Nenhum dos escolares do GC apresentava, à época da avaliação, qualquer indicação de evidências de dificuldades na leitura e escrita. Eram todos matriculados em uma mesma escola da rede particular de ensino, situada na zona sul do município de São Paulo-SP e foram selecionados a partir da indicação dos professores da escola, que foram solicitados a encaminhar escolares sem queixas ou evidências de dificuldades na leitura e escrita.

\section{Procedimentos}

A avaliação constou de duas etapas:

\section{Ditado de itens lingüísticos:}

Inicialmente, elaborou-se uma lista de 30 itens lingüísticos isolados (dissilábicos e trissilábicos), composta por palavras e pseudopalavras escritas apenas com estruturas silábicas do tipo $\mathrm{CV}$ e as seguintes consoantes, em freqüência variável de aparecimento: p, b, t, d, f, v, m, n, e os dígrafos nh e lh (Quadro $1)$. Todos os itens respeitaram a regra ortográfica de correspon-

Quadro 1. Distribuição das consoantes nos diferentes itens lingüísticos

\begin{tabular}{|ccccc|}
\hline Letras ou dígrafos & $\begin{array}{c}\text { Palavras de alta } \\
\text { freqüência }\end{array}$ & $\begin{array}{c}\text { Palavras de baixa } \\
\text { freqüência }\end{array}$ & Pseudopalavras & Total \\
\hline P & 3 & 1 & 2 & 6 \\
B & 2 & 2 & 2 & 6 \\
T & 5 & 3 & 3 & 11 \\
D & 3 & 3 & 2 & 8 \\
F & 3 & 0 & 3 & 6 \\
V & 1 & 3 & 3 & 7 \\
M & 1 & 1 & 2 & 4 \\
N & 0 & 4 & 3 & 5 \\
NH & 1 & 2 & 2 & 6 \\
LH & 2 & 2 & 2 & 5 \\
\hline
\end{tabular}


dência direta e independente do contexto para a codificação. A seleção foi realizada de acordo com as indicações de Scliar$\mathrm{Cabral}^{(28)}$. Para a elaboração da lista obedeceu-se à variável psicolingüística frequiência de ocorrência. Foram escolhidas 10 palavras de alta frequiência e 10 de baixa frequiência e criadas 10 pseudopalavras. Contou-se, para isso, com o auxílio de professores do Ensino Fundamental para a seleção das palavras segundo a indicação de sua freqüência de aparecimento a partir da análise de livros didáticos de $1^{\mathrm{a}} \mathrm{a} 4^{\mathrm{a}}$ série.

Os itens foram selecionados e classificados da seguinte forma, de acordo com a freqüência de aparecimento: 1. Palavras de alta freqüência: tatu, fada, minha, pato, povo, bode, bife, folha, apito, telhado; 2. Palavras de baixa frequiência: diva, anu, nata, bilha, tupi, neve, ninho, tuba, velhinha, domado; 3 . Pseudopalavras: tupa, dafe, tavu, funhe, nolha, buva, vibona, fanhota, nupemi, malhedo.

Os escolares foram, então, submetidos à aplicação do ditado de forma individual, em sala silenciosa, arejada e iluminada adequadamente. Para a realização do ditado foi entregue a cada criança uma folha de registro pautada, (papel sulfite A4) e um lápis preto $\mathrm{n}^{\circ} 2$.

Para a análise dos erros, estes foram contados admitindo-se a possibilidade de aparecimento de mais de um em cada item lingüístico. Foram computados os seguintes erros pertinentes ao uso da regra de correspondência direta independente do contexto de escrita: substituições, omissões, inversões e duplicações de letras (consoantes ou vogais). Também foram consideradas as inversões nos dígrafos.

\section{Coleta de justificativas:}

Após o ditado dos 30 itens, foi solicitado a cada escolar que relesse o que havia escrito e assinalasse um "X", entre os parênteses posicionados ao lado de cada item sempre que julgasse tê-lo escrito corretamente. Em seguida, que justificasse, oralmente, cada acerto ou cada erro identificado nos itens escritos que não foram assinalados. Após a identificação do erro, foi perguntado ao escolar: "Onde você acha que está errado?" e, em seguida, "Por que você acha que está errado?". Neste trabalho, considerou-se como justificativa desde a correção da letra até a referência quanto à familiaridade com a palavra. Todas as justificativas foram gravadas, para posterior transcrição canônica e análise dos resultados.

Quanto à análise, as justificativas foram classificadas e valoradas segundo quatro tipos, conforme o descrito:

Tipo A - Quando a criança escreveu corretamente e justificou corretamente sua escrita. Considerou-se como justificativa mesmo quando a criança referiu apenas que a palavra escrita estava certa. Do ponto de vista do conhecimento que a criança tinha sobre o uso da regra ortográfica pesquisada, considerouse esta justificativa como Muito Boa e atribui-se a ela o valor de quatro pontos.

Tipo B - Quando a criança escreveu incorretamente, identificou um ou mais erro(s) em cada item, e justificouo(s) corretamente. Do ponto de vista do conhecimento que a criança tinha sobre o uso da regra ortográfica pesquisada, considerou-se esta justificativa como Boa e atribuiu-se a ela o valor de três pontos.

Tipo C - Quando a criança escreveu incorretamente, iden- tificou um ou mais erro(s) em cada palavra e justificou-o(s) incorretamente, ou, quando a criança escreveu corretamente a palavra, identificou um ou mais erro(s) e justificou-o(s) incorretamente. Do ponto de vista do conhecimento que a criança tinha sobre o uso da regra ortográfica pesquisada, consideraram-se estas justificativas como Regulares e atribuiuse a elas o valor de dois pontos.

Tipo D - Quando a criança escreveu incorretamente, não identificou e não justificou o(s) erro(s). Do ponto de vista do conhecimento que a criança tinha sobre o uso da regra ortográfica pesquisada, considerou-se esta justificativa como Fraca e atribuiu-se a ela o valor de um ponto.

Considerou-se justificativa correta quando o escolar localizou, com exatidão, na palavra, a(s) letra(s) incorreta(s) e corrigiu, oralmente, o erro.

Considerou-se justificativa incorreta quando o escolar não localizou, com exatidão, a(s) letra(s) incorreta(s) ou não corrigiu, oralmente, o erro.

\section{Método estatístico}

Para a análise estatística dos resultados obtidos nesta pesquisa foi utilizado o teste de Análise de Variância (ANOVA), com nível de significância de 5\%.

No presente estudo diversos efeitos foram considerados nas várias comparações realizadas. Como efeitos independentes estudaram-se Grupo (GC x GP) e Série (1 $1^{\mathrm{a}}, 2^{\mathrm{a}}, 3^{\mathrm{a}}$ e $4^{\mathrm{a}}$ ). Como efeitos dependentes estudaram-se os tipos de itens lingüísticos (alta freqüência, baixa frequiência e pseudopalavras).

A quantidade de erros, por letra, foi calculada em porcentagem, a partir da possibilidade de eventos de escrita de cada letra, em cada tipo de item lingüístico, para cada série.

\section{RESULTADOS}

A comparação entre os erros produzidos pelos dois grupos mostrou que o GP produziu mais erros que o $\mathrm{GC}$ em todas as combinações de série e item linguístico. Ao analisar o desempenho isolado do GP foi possível observar, que este produziu menos erros ao escrever palavras de alta frequiência, em todas as séries em relação aos demais tipos de itens lingüísticos e mais erros em não palavras, na $1^{\mathrm{a}}$ série (Tabelas 1 e 2). O GC não mostrou diferenças quanto ao tipo de item lingüístico.

A comparação entre a porcentagem de erros, produzida por letra, pelas crianças de $1^{\mathrm{a}}$ a $4^{\mathrm{a}}$ série do GP, nos três tipos de itens lingüísticos, apresentada na Tabela 3 , mostra que, em ordem decrescente de frequiência de aparecimento os erros foram: os do dígrafo $\mathrm{lh}$, seguidos do dígrafo nh, da letra $\mathrm{m}$, da letra d e, finalmente, da letra n. Quanto ao tipo de item lingüístico, apareceram mais erros nas pseudopalavras, seguidos das palavras de baixa freqüência e das palavras de alta freqüência. Observou-se, ainda, que houve uma redução do número total de erros por letra conforme a progressão das séries, no GP.

A comparação entre a porcentagem de erros por letra produzidos por crianças de $1^{\mathrm{a}}$ a $4^{\mathrm{a}}$ série do GC nos três tipos de itens lingüísticos, apresentada na Tabela 4, mostra que em ordem decrescente de frequiência de aparecimento, os erros 
Tabela 1. Médias e desvios-padrão do número de erros produzidos por crianças de ambos os grupos, segundo o item lingüístico e a série

\begin{tabular}{|c|c|c|c|c|c|c|c|c|c|c|c|c|c|}
\hline \multirow[t]{3}{*}{ Grupo } & \multirow[t]{3}{*}{ Estatísticas } & \multicolumn{4}{|c|}{ Alta freqüência } & \multicolumn{4}{|c|}{ Baixa freqüência } & \multicolumn{4}{|c|}{ Pseudopalavras } \\
\hline & & \multicolumn{4}{|c|}{ Séries } & \multicolumn{4}{|c|}{ Séries } & \multicolumn{4}{|c|}{ Séries } \\
\hline & & $1^{\mathrm{a}}$ & $2^{a}$ & $3^{\mathrm{a}}$ & $4^{a}$ & $1^{a}$ & $2^{a}$ & $3^{a}$ & $4^{a}$ & $1^{a}$ & $2^{\mathrm{a}}$ & $3^{a}$ & $4^{a}$ \\
\hline \multirow[t]{3}{*}{ GP } & Média & 2,40 & 1,00 & 1,40 & 0,67 & 3,40 & 1,75 & 2,60 & 1,67 & 5,60 & 1,67 & 2,80 & 1,17 \\
\hline & Desvio-padrão & 1,67 & 1,48 & 2,61 & 0,82 & 2,41 & 1,42 & 1,82 & 1,37 & 3,36 & 2,02 & 3,56 & 1,47 \\
\hline & $\mathrm{N}$ & 5 & 12 & 5 & 6 & 5 & 12 & 5 & 6 & 5 & 12 & 5 & 6 \\
\hline \multirow[t]{3}{*}{$\mathrm{GC}$} & Média & 0 & 0,08 & 0,20 & 0 & 0,80 & 0,67 & 0,80 & 0,50 & 0,60 & 0,33 & 0 & 0,33 \\
\hline & Desvio-padrão & 0 & 0,29 & 0,45 & 0 & 0,45 & 0,49 & 0,45 & 0,55 & 0,89 & 0,49 & 0 & 0,52 \\
\hline & $\mathrm{N}$ & 5 & 12 & 5 & 6 & 5 & 12 & 5 & 6 & 5 & 12 & 5 & 6 \\
\hline
\end{tabular}

Teste Estatístico: Teste de Análise de Variância (ANOVA), com nível de significância de 5\%.

Tabela 2. Análise de variância (ANOVA)

\begin{tabular}{lc}
\hline Efeito & Significância de $F(p)$ \\
\hline Grupo & $<0,0001^{*}$ \\
Série & 0,0588 \\
Tipo de item lingüístico & $<0,0001^{*}$ \\
Grupo x Série & 0,1085 \\
Grupo x Tipo & $0,0008^{*}$ \\
Série x Tipo & 0,0146 * \\
Grupo x Série x Tipo & 0,0519 \\
\hline
\end{tabular}

* Teste Estatístico: Teste de Análise de Variância (ANOVA), com nível de significância de 5\%.

foram: os do dígrafo $\mathrm{lh}$, seguidos dos da letra $\mathrm{m}$, da letra $\mathrm{f}$, e finalmente, da letra n. A Tabela 4 mostra, ainda, que o GC, não apresentou erros ao escrever com as letras $b, t, d, v$ e o dígrafo nh.

Nas Tabelas 5 e 6, apresentam-se os valores das médias e dos desvios-padrão do número total de pontos e a Análise de Variância, considerando a categorização de erros quanto à identificação e justificativas dos tipos A, B, C e D produzidas por crianças de ambos os grupos em palavras de alta freqüência, baixa freqüência e pseudopalavras, segundo a série.

Inicialmente, comparam-se os totais de pontos obtidos, por cada série de cada grupo, a partir da soma dos valores atribuídos a todas as justificativas. De forma geral, GC teve escores maiores que o GP em todas as combinações de série e tipo ( $\mathrm{p}=0,0001)$. Quanto aos tipos de item lingüístico, não houve diferenças significantes para os escores de justificativas no GP. Já no GC observa-se escore maior nas justificativas fornecidas para erros da escrita de palavras de alta freqüência nas três primeiras séries.

Por meio de comparações entre os grupos, as séries, os tipos de itens lingüísticos, observa-se que as justificativas do tipo A apresentaram maior pontuação, quando comparada com as outras justificativas em ambos os grupos. Observa-se, ainda, na comparação entre os dois grupos que as justificativas A e $\mathrm{C}$ apresentaram maior pontuação no GC quando comparadas com o GP.

Da mesma forma, as justificativas B e D apresentaram maior pontuação no GP quando comparado com o GC. Verifica-se, também, na comparação entre os tipos de itens lingüísticos que a maior pontuação da justificativa do tipo
Tabela 3. Porcentagem de erros por letra, produzidos por crianças de $1^{a}$ a $4^{a}$ série do GP em palavras de alta freqüência, baixa freqüência e pseudopalavras

\begin{tabular}{|c|c|c|c|c|c|}
\hline \multirow[t]{2}{*}{ Letra } & \multirow[t]{2}{*}{ Variável psicolingüística } & \multicolumn{4}{|c|}{ Séries } \\
\hline & & $1^{\mathrm{a}}$ & $2^{\mathrm{a}}$ & $3^{a}$ & $4^{a}$ \\
\hline \multirow[t]{3}{*}{$P$} & Alta freqüência & 0 & 0 & 20,00 & 0 \\
\hline & Baixa freqüência & 20,00 & 0 & 20,00 & 0 \\
\hline & Pseudopalavras & 20,00 & 0 & 10,00 & 0 \\
\hline \multirow[t]{3}{*}{ B } & Alta freqüência & 0 & 4,17 & 0 & 8,33 \\
\hline & Baixa freqüência & 0 & 8,34 & 10,00 & 0 \\
\hline & Pseudopalavras & 0 & 0 & 0 & 0 \\
\hline \multirow[t]{3}{*}{$\mathrm{T}$} & Alta freqüência & 0 & 1,67 & 4,00 & 0 \\
\hline & Baixa freqüência & 6,67 & 0 & 20,00 & 0 \\
\hline & Pseudopalavras & 13,34 & 2,78 & 6,67 & 0 \\
\hline \multirow[t]{3}{*}{ D } & Alta freqüência & 6,67 & 8,34 & 0 & 5,56 \\
\hline & Baixa freqüência & 6,67 & 8,34 & 6,67 & 0 \\
\hline & Pseudopalavras & 20,00 & 8,34 & 6,67 & 0 \\
\hline \multirow[t]{3}{*}{$\mathrm{F}$} & Alta freqüência & 6,67 & 2,78 & 6,67 & 0 \\
\hline & Baixa freqüência & 0 & 0 & 0 & 0 \\
\hline & Pseudopalavras & 20,00 & 0 & 0 & 6,00 \\
\hline \multirow[t]{3}{*}{ V } & Alta freqüência & 0 & 0 & 0 & 0 \\
\hline & Baixa freqüência & 0 & 0 & 0 & 0 \\
\hline & Pseudopalavras & 13,34 & 2,78 & 13,34 & 6,00 \\
\hline \multirow[t]{3}{*}{ M } & Alta freqüência & 0 & 8,33 & 0 & 0 \\
\hline & Baixa freqüência & 0 & 16,67 & 6,67 & 0 \\
\hline & Pseudopalavras & 30,00 & 16,67 & 20,00 & 16,67 \\
\hline \multirow[t]{3}{*}{$\mathrm{N}$} & Alta freqüência & 0 & 0 & 0 & 0 \\
\hline & Baixa freqüência & 10,00 & 2,10 & 5,00 & 8,34 \\
\hline & Pseudopalavras & 13,34 & 2,78 & 13,34 & 6,00 \\
\hline \multirow[t]{3}{*}{$\mathrm{NH}$} & Alta freqüência & 40,00 & 8,33 & 0 & 16,67 \\
\hline & Baixa freqüência & 40,00 & 8,34 & 10,00 & 25,00 \\
\hline & Pseudopalavras & 60,00 & 25,00 & 30,00 & 8,34 \\
\hline \multirow[t]{3}{*}{ LH } & Alta freqüência & 80,00 & 16,67 & 20,00 & 8,33 \\
\hline & Baixa freqüência & 80,00 & 46,00 & 40,00 & 42,00 \\
\hline & Pseudopalavras & 60,00 & 21,00 & 30,00 & 8,34 \\
\hline
\end{tabular}

Teste Estatístico: Teste de Análise de Variância (ANOVA), com nível de significância de $5 \%$. 
Tabela 4. Porcentagem de erros por letra, produzidos por crianças de $1^{a}$ a $4^{a}$ série do GC em palavras de alta freqüência, baixa freqüência e pseudopalavras

\begin{tabular}{|c|c|c|c|c|c|}
\hline \multirow[t]{2}{*}{ Letra } & \multirow[t]{2}{*}{ Variável psicolingüística } & \multicolumn{4}{|c|}{ Séries } \\
\hline & & $1^{a}$ & $2^{a}$ & $3^{a}$ & $4^{a}$ \\
\hline \multirow[t]{3}{*}{$P$} & Alta freqüência & 0 & 2,78 & 0 & 0 \\
\hline & Baixa freqüência & 0 & 0 & 0 & 0 \\
\hline & Pseudopalavras & 0 & 0 & 0 & 0 \\
\hline \multirow[t]{3}{*}{ B } & Alta freqüência & 0 & 0 & 0 & 0 \\
\hline & Baixa freqüência & 0 & 0 & 0 & 0 \\
\hline & Pseudopalavras & 0 & 0 & 0 & 0 \\
\hline \multirow[t]{3}{*}{$\mathrm{T}$} & Alta freqüência & 0 & 0 & 0 & 0 \\
\hline & Baixa freqüência & 0 & 0 & 0 & 0 \\
\hline & Pseudopalavras & 0 & 0 & 0 & 0 \\
\hline \multirow[t]{3}{*}{ D } & Alta freqüência & 0 & 0 & 0 & 0 \\
\hline & Baixa freqüência & 0 & 0 & 0 & 0 \\
\hline & Pseudopalavras & 0 & 0 & 0 & 0 \\
\hline \multirow[t]{3}{*}{$\mathrm{F}$} & Alta freqüência & 0 & 0 & 20,00 & 0 \\
\hline & Baixa freqüência & 0 & 0 & 0 & 0 \\
\hline & Pseudopalavras & 6,67 & 0 & 0 & 6,00 \\
\hline \multirow[t]{3}{*}{ V } & Alta freqüência & 0 & 0 & 0 & 0 \\
\hline & Baixa freqüência & 0 & 0 & 0 & 0 \\
\hline & Pseudopalavras & 0 & 0 & 0 & 0 \\
\hline \multirow[t]{3}{*}{ M } & Alta freqüência & 0 & 0 & 0 & 0 \\
\hline & Baixa freqüência & 0 & 0 & 0 & 0 \\
\hline & Pseudopalavras & 20,00 & 8,34 & 0 & 0 \\
\hline \multirow[t]{3}{*}{$\mathrm{N}$} & Alta freqüência & 0 & 0 & 0 & 0 \\
\hline & Baixa freqüência & 5,00 & 0 & 5,00 & 0 \\
\hline & Pseudopalavras & 0 & 2,78 & 0 & 0 \\
\hline \multirow[t]{3}{*}{$\mathrm{NH}$} & Alta freqüência & 0 & 0 & 0 & 0 \\
\hline & Baixa freqüência & 0 & 0 & 0 & 0 \\
\hline & Pseudopalavras & 0 & 0 & 0 & 0 \\
\hline \multirow[t]{3}{*}{ LH } & Alta freqüência & 0 & 0 & 0 & 0 \\
\hline & Baixa freqüência & 30,00 & 33,34 & 30,00 & 25,00 \\
\hline & Pseudopalavras & 0 & 4,17 & 0 & 8,34 \\
\hline
\end{tabular}

Teste Estatístico: Teste de Análise de Variância (ANOVA), com nível de significância de $5 \%$.

A ocorreu para palavras de alta freqüência e a ocorrência de maior pontuação da justificativa do tipo D para a análise da escrita das pseudopalavras.

\section{DISCUSSÃO}

O procedimento selecionado para esta pesquisa foi a aplicação de ditado de itens lingüísticos. A escolha da regra de correspondência grafo-fonêmica independente do contexto e de itens lingüísticos de estrutura silábica simples (CV) tornou a escrita dos escolares, a mais fundamental e mais próxima possível de uma escrita que poderia ser considerada fonológica. Mesmo assim, foi possível observar que os escolares do GP erraram mais que os do GC, em todas as séries e em todos os itens lingüísticos, ao escreverem as palavras e pseudopalavras, sendo esta diferença estatisticamente significante (Tabelas 1 e 2).

Apesar de não terem estudado isoladamente a regra de correspondência direta, outras pesquisas da literatura também relataram pior desempenho em todas as tarefas de escrita de grupos de alunos com dificuldades no aprendizado da leitura e da escrita ${ }^{(2-4,9,13)}$.

Não obstante esse pior desempenho, quando se analisou o comportamento do GP isoladamente, pôde-se perceber que houve diminuição progressiva do número de erros, da $1^{\mathrm{a}}$ à $2^{\mathrm{a}}$ série e da $3^{\mathrm{a}}$ à $4^{\mathrm{a}}$ série mostrando o efeito da escolarização, também, sobre a escrita dos escolares do GP. Ou seja, apesar do transtorno esse grupo mostrou que foi capaz de aprender e progredir, em algum grau, no domínio do princípio alfabético e no aprendizado da escrita ${ }^{(4-5,12,17,19,24)}$.

A comparação entre os grupos mostrou-se diferente também porque os escolares do GC mostraram desempenho uniforme ao longo das séries.

Portanto, esta diferença entre os desempenhos caracterizou o GP pelas dificuldades na capacidade de codificar fonemas em grafemas, segundo a regra de representação direta e independente do contexto da escrita. O aprendizado e o domínio desta regra, sendo diretamente relacionados à aprendizagem do escolar ${ }^{28)}$, sustentam-se, principalmente, no desenvolvimento de capacidades metacognitivas relacionadas ao conhecimento de que as letras representam os sons da fala ${ }^{(7)}$.

Observou-se, também, que o GP produziu menos erros ao escrever palavras de alta freqüência em relação aos demais tipos de itens lingüísticos, sendo esta diferença estatisticamente significante (Tabelas 1 e 2). Ou seja, os resultados mostraram uma predominância de erros na escrita de palavras de baixa frequiência e pseudopalavras de ortografia transparente evidenciando que a familiaridade com o estímulo pôde garantir maior precisão na escrita. Estes achados corroboram outro ${ }^{(2)}$, que afirmou ser a escrita sensível à frequiência de aparecimento das palavras. O maior número de erros encontrados na escrita das palavras de baixa freqüência, quando comparado ao dos escolares do GC, evidenciou a dificuldade dos escolares do GP para apreender representações lexicais de uma nova palavra, ou de realizar o processamento ortográfico.

A simples comparação numérica entre a quantidade de erros cometidos pelos escolares das diferentes séries do GP, em especial os da $4^{\mathrm{a}}$ série, mostrou que estes erraram mais do que os escolares da $1^{\mathrm{a}}$ série do GC evidenciando a discrepância entre os desempenhos dos dois grupos, mesmo na escrita de transparência ortográfica ${ }^{(2,8,28)}$. Portanto, poder-se-ia pensar que se a criança apresenta dificuldade na utilização e domínio desta regra de correspondência direta independente do contexto já nas séries iniciais, a dificuldade de aprendizado ortográfico poderia se estender ou ainda, se agravar nas séries consecutivas $^{(10-11,13,22,24)}$. Semelhantemente aos resultados desta pesquisa, outro estudo observou que estudantes de $5^{a}$ série ainda apresentavam dificuldades no domínio dessa regra ${ }^{(5)}$.

Estes resultados indicam que, como a regra estudada não recebe interferência do contexto morfossintático da escrita, o escolar necessitará de auxílio para desenvolver competências metalingüísticas que contribuam para o aprendizado do princípio alfabético ou da associação fonema-grafema. 
Tabela 5. Médias e desvios-padrão do total de pontos na categorização de erros quanto à identificação e à justificativa produzida por crianças do GP e do GC segundo o item lingüístico e a série

\begin{tabular}{|c|c|c|c|c|c|c|c|c|c|c|c|c|c|c|}
\hline \multirow{3}{*}{ Grupo } & \multirow{3}{*}{ Justificativa } & \multirow{3}{*}{ Estatísticas } & \multicolumn{4}{|c|}{ Alta freqüência } & \multicolumn{4}{|c|}{ Baixa freqüência } & \multicolumn{4}{|c|}{ Pseudopalavras } \\
\hline & & & \multicolumn{4}{|c|}{ Séries } & \multicolumn{4}{|c|}{ Séries } & \multicolumn{4}{|c|}{ Séries } \\
\hline & & & $1^{\mathrm{a}}$ & $2^{\mathrm{a}}$ & $3^{a}$ & $4^{a}$ & $1^{\mathrm{a}}$ & $2^{\mathrm{a}}$ & $3^{a}$ & $4^{a}$ & $1^{\mathrm{a}}$ & $2^{\mathrm{a}}$ & $3^{a}$ & $4^{a}$ \\
\hline \multirow{12}{*}{ GP } & \multirow{3}{*}{ A } & Média & 20,80 & 29,33 & 30,40 & 30,00 & 18,40 & 27,67 & 24,80 & 31,33 & 16,00 & 27,33 & 24,80 & 28,67 \\
\hline & & Desvio-padrão & 11,80 & 5,74 & 11,17 & 6,07 & 10,81 & 4,66 & 7,16 & 4,68 & 10,20 & 8,33 & 10,73 & 5,89 \\
\hline & & $\mathrm{n}$ & 5 & 12 & 5 & 6 & 5 & 12 & 5 & 6 & 5 & 12 & 5 & 6 \\
\hline & \multirow{3}{*}{ B } & Média & 2,40 & 1,00 & 1,20 & 2,50 & 3,60 & 1,00 & 2,40 & 1,50 & 3,00 & 1,00 & 0,60 & 0,00 \\
\hline & & Desvio-padrão & 5,37 & 2,34 & 2,68 & 2,26 & 3,29 & 1,48 & 3,29 & 1,64 & 5,20 & 1,48 & 1,34 & 0,00 \\
\hline & & $\mathrm{n}$ & 5 & 12 & 5 & 6 & 5 & 12 & 5 & 6 & 5 & 12 & 5 & 6 \\
\hline & \multirow{3}{*}{ C } & Média & 4,0 & 0,8 & 0,4 & 0,3 & 4,4 & 1,5 & 1,2 & 1,0 & 3,6 & 1,8 & 1,2 & 0,7 \\
\hline & & Desvio-padrão & 4,2 & 1,3 & 0,9 & 0,8 & 3,0 & 2,3 & 1,1 & 1,1 & 4,1 & 2,8 & 1,8 & 1,0 \\
\hline & & $\mathrm{n}$ & 5 & 12 & 5 & 6 & 5 & 12 & 5 & 6 & 5 & 12 & 5 & 6 \\
\hline & \multirow{3}{*}{ D } & Média & 3,4 & 2,2 & 1,8 & 2,2 & 5,0 & 2,8 & 3,6 & 1,8 & 7,6 & 2,6 & 5,4 & 2,8 \\
\hline & & Desvio-padrão & 3,8 & 1,3 & 2,9 & 1,7 & 5,6 & 1,7 & 3,3 & 2,0 & 6,7 & 2,2 & 5,5 & 2,0 \\
\hline & & $\mathrm{n}$ & 5 & 12 & 5 & 6 & 5 & 12 & 5 & 6 & 5 & 12 & 5 & 6 \\
\hline \multirow{12}{*}{ GC } & \multirow{3}{*}{ A } & Média & 36,80 & 37,33 & 38,40 & 34,67 & 32,00 & 33,67 & 28,80 & 32,00 & 28,00 & 33,33 & 29,60 & 31,33 \\
\hline & & Desvio-padrão & 3,35 & 3,55 & 2,19 & 3,27 & 8,00 & 5,52 & 11,10 & 7,16 & 9,38 & 5,74 & 12,52 & 8,16 \\
\hline & & $\mathrm{n}$ & 5 & 12 & 5 & 6 & 5 & 12 & 5 & 6 & 5 & 12 & 5 & 6 \\
\hline & \multirow{3}{*}{ B } & Média & 0,60 & 0,75 & 0,60 & 0,00 & 0,00 & 0,00 & 0,60 & 0,00 & 0,60 & 0,50 & 0,00 & 0,00 \\
\hline & & Desvio-padrão & 1,34 & 1,86 & 1,34 & 0,00 & 0,00 & 0,00 & 1,34 & 0,00 & 1,34 & 1,17 & 0,00 & 0,00 \\
\hline & & $\mathrm{n}$ & 5 & 12 & 5 & 6 & 5 & 12 & 5 & 6 & 5 & 12 & 5 & 6 \\
\hline & \multirow{3}{*}{ C } & Média & 0,4 & 0,8 & 0,0 & 1,7 & 2,0 & 2,2 & 3,6 & 2,3 & 2,8 & 2,2 & 4,8 & 2,3 \\
\hline & & Desvio-padrão & 0,9 & 1,6 & 0,0 & 1,5 & 3,5 & 2,9 & 5,4 & 3,2 & 3,0 & 2,5 & 5,8 & 2,7 \\
\hline & & $\mathrm{n}$ & 5 & 12 & 5 & 6 & 5 & 12 & 5 & 6 & 5 & 12 & 5 & 6 \\
\hline & \multirow{3}{*}{$\mathrm{D}$} & Média & 0,6 & 0,0 & 0,4 & 0,5 & 1,0 & 0,5 & 0,8 & 0,8 & 1,4 & 0,5 & 0,2 & 1,2 \\
\hline & & Desvio-padrão & 0,5 & 0,0 & 0,5 & 0,5 & 0,7 & 0,7 & 0,4 & 0,4 & 0,9 & 0,7 & 0,4 & 1,9 \\
\hline & & $\mathrm{N}$ & 5 & 12 & 5 & 6 & 5 & 12 & 5 & 6 & 5 & 12 & 5 & 6 \\
\hline
\end{tabular}

Teste Estatístico: Teste de Análise de Variância (ANOVA), com nível de significância de 5\%.

Tabela 6. Análise de variância (ANOVA)

\begin{tabular}{lc}
\hline Efeito & Significância de F (p) \\
\hline Grupo (com TLE x sem TLE) & $0,0009^{*}$ \\
Série (1a x 2a x 3a x 4a) & 0,4119 \\
Tipo de item lingüístico (Alta fq x Baixa Fq & $0,0004^{*}$ \\
x Pseudopal) & \\
Justificativa (A x B x C x D) & $<0,0001^{*}$ \\
Grupo x Série & 0,6104 \\
Grupo x Tipo & 0,0399 * \\
Grupo x Justificativa & $<0,0001^{*}$ \\
Série x Tipo & 0,5742 \\
Série x Justificativa & 0,0218 * \\
Tipo x Justificativa & $<0,0001$ * \\
Grupo x Série x Tipo & 0,8083 \\
Grupo x Série x Justificativa & 0,1480 \\
Grupo x Tipo x Justificativa & 0,0494 * \\
Série x Tipo x Justificativa & 0,0558 \\
Grupo x Série x Tipo x Justificativa & 0,9894
\end{tabular}

Teste Estatístico: Teste de Análise de Variância (ANOVA), com nível de significância de $5 \%$.

Legenda: TLE: transtorno específico de leitura
Na presente pesquisa, o número de erros apresentados pelas crianças do GC indicou que estas tinham poucas dificuldades no uso da regra de correspondência fono-grafêmica, independente do contexto, desde as primeiras séries do ensino fundamental como já era esperado. Este resultado concorda com estudo que mostrou que mesmo as palavras de alta freqüência podem ser escritas com mais correção somente por crianças sem transtorno do aprendizado ${ }^{(8)}$.

Quanto ao efeito de familiaridade do item lingüístico, pôde-se perceber que o GP produziu menos erros ao escrever palavras de alta frequiência em relação aos demais itens lingüísticos. Portanto, pode-se admitir que o efeito lexical também influenciou a escrita dos escolares do GP, desde os estágios iniciais do aprendizado, com vantagem na produção de um item familiar sobre a produção de outro, menos ou não familiar $^{(2,13)}$.

O conhecimento de certas características ortográficas pode, também, ser testado com a escrita de pseudopalavras, requerendo como capacidade mínima a eficiência na conversão fonema-grafema. Pode-se pensar que a criança tenha adquirido o domínio da regra ortográfica analisada, quando também consiga escrever pseudopalavras corretamente e não somente as palavras. Assim, a inclusão de pseudopalavras permitirá verificar o uso gerativo da ortografia por parte da criança $a^{(3)}$. 
Além disso, um pior desempenho na escrita das pseudopalavras indicaria a presença de prejuízos no processamento de informações fonológicas ${ }^{(1,9)}$. De fato, nesta pesquisa, a $1^{a}$ série do GP apresentou mais erros quando comparada com a $2^{\mathrm{a}}$ e $4^{\mathrm{a}}$ séries, principalmente ao escrever as pseudopalavras. Outra pesquisa também descreveu a presença de pior desempenho ortográfico na $1^{\mathrm{a}}$ série, principalmente com a escrita de palavras inventadas $^{(2)}$.

Devido ao tamanho da amostra, não foi possível comparar estatisticamente, a porcentagem de erros por letra produzidos pelos dois grupos. Entretanto, a análise descritiva das porcentagens pode levar a algumas considerações interessantes quanto ao tipo de erro ou à letra errada.

Assim, observou-se, inicialmente que, independentemente do grupo, os escolares desta pesquisa apresentaram menor dificuldade, ou seja, menor número de erros ao escreverem palavras que contivessem as letras b, f, e v. Estes achados são condizentes com um estudo encontrado na literatura ${ }^{(4)}$.

Observou-se, entretanto, maior dificuldade ao representar os dígrafos nh e lh em todos os tipos de itens linguiísticos para ambos os grupos, seguidos das letras $\mathrm{m}, \mathrm{d}$ e n, principalmente na $1^{\mathrm{a}}$ série.

Apesar das diferenças ortográficas dos idiomas, há um estudo que também encontrou proporções semelhantes de erros em ditados com palavras escritas com as mesmas letras, entre outras, ao estudarem crianças com dislexia ${ }^{(9)}$.

Quanto aos erros de escrita, caracterizados por substituições de letras, estiveram mais relacionados ao traço lingüístico distintivo da sonoridade. Apesar da diferença de metodologia, bem como da amostra estudada, há uma pesquisa que dá suporte a estes resultados, na medida em que referiu serem as trocas surdo-sonoras as segundas mais freqüentemente apresentadas pelos escolares avaliados ${ }^{(5)}$.

O GC (Tabela 4) mostrou maior número de erros apenas ao escrever palavras de baixa freqüência com o dígrafo $\mathrm{lh}$, assemelhando-se nesse ponto ao GP, apesar da menor freqüência de ocorrência como encontrado em outro estudo ${ }^{(4)}$.

Outro aspecto a ser considerado, na escrita das crianças de ambos os grupos, é a aproximação acústica de $/ \lambda /$ e a consoante /1/ ao se co-articularem, ambos, com /i/, mais precisamente na palavra "velhinha". Esta aproximação pode ter prejudicado a recepção do que foi ditado, ocasionando a pontuação elevada com relação ao uso deste dígrafo neste item lingüístico. $\mathrm{Na}$ fala, os componentes não são perceptivamente claros devido à co-articulação entre os fonemas. Existe uma variação extrema da característica acústica, dependendo do contexto no qual o fonema está inserido, cortando a correspondência entre unidades escritas. Assim, pode-se considerar que os escolares, de ambos os grupos interpretaram "velhinha" como "velinha", aumentando assim o número de erros. Este resultado sugere que a utilização desse item deve ser revista.

Antes mesmo da alfabetização, crianças começam a refletir sobre a natureza segmentada da fala, de forma a tornar possível a compreensão de como as palavras são escritas. Esse conhecimento é explícito e reflexivo e deve ser compreendido diferentemente da sensibilidade inata que sustenta a recepção e produção da fala. A consciência fonológica contribui, principalmente, para a aquisição de regras de contexto grafofônico. As alterações destas capacidades estão presentes nos quadros de Transtorno Específico da Leitura, dificultando inicialmente o aprendizado do princípio alfabético e, em conseqüência, o processamento ortográfico e o advento da escrita ortográfica correta.

$\mathrm{O}$ estudo das justificativas fornecidas pelos escolares avaliados pode contribuir para o conhecimento de outras capacidades metacognitivas e metalingüísticas, não apenas as metafonológicas. Nesta pesquisa, as justificativas foram comparadas segundo o grupo a que pertenciam os escolares, o tipo de item linguiístico e as séries.

Assim, na comparação entre os dois grupos verificou-se que a justificativa A foi a mais pontuada por ambos os grupos, enquanto as justificativas B e D apresentaram maior pontuação no GP.

A análise comparativa entre os grupos mostrou maior pontuação da justificativa A obtida pelo GC o qual identificou corretamente os itens lingüísticos escritos de forma adequada, justificando, automaticamente os seus acertos (mais freqüentes que no GP) e com mais exatidão, do que os escolares do GP. Entretanto, os escolares do GC também indicaram a presença de erro em palavras que, apesar de suas respostas, haviam escrito corretamente. Os erros foram indicados principalmente por alunos da $3^{\mathrm{a}}$ série e relacionavam-se à ausência de acentuação em palavras que não necessitavam de acentos ortográficos ${ }^{(6)}$.

Já os escolares do GP utilizaram mais as justificativas do tipo B e principalmente do D. Este resultado mostrou que alguns escolares do GP não conseguiram identificar ou justificar erros, em grande parte das vezes em que foram solicitados a fazê-lo. Por outro lado, esse grupo de escolares também pontuou mais a justificativa do tipo B, quando comparado ao GC, evidenciando a capacidade de identificar e justificar corretamente alguns dos erros que cometeram ao escrever, quando solicitados a fazê-lo. Ou seja, mostraram que são dotados de capacidades metalingüísticas e metacognitivas de análise dos erros da própria produção escrita. E que, apesar de seus erros, o aprendizado mais adequado é possível, indicando que programas de remediação e reabilitação, baseados na consciência ortográfica e na estimulação da clareza metagráfica, podem ser eficazes.

Estes resultados diferem de outro estudo no qual as crianças de escolas públicas, sem alterações de aprendizagem, tiveram dificuldade em identificar um erro de escrita. Alguns alunos com melhor desempenho na escrita verbalizaram as regras ortográficas alteradas, mesmo sem usar termos especiais e outros, com o pior desempenho na escrita, revelaram uma quase impossibilidade de verbalizar as regras ${ }^{(1)}$.

A avaliação da escrita deve possibilitar à criança a oportunidade de analisar suas respostas ao mesmo tempo em que constrói suas aprendizagens, salientando junto com o avaliador seus pontos fortes e fracos ${ }^{(1,29)}$. Os resultados desta pesquisa indicaram que isso é possível, uma vez que mesmo os escolares do GP foram capazes de construir justificativas, algumas corretas, para seus erros de escrita.

A participação ativa da criança na avaliação promove o desenvolvimento do domínio de estratégias metacognitivas que lhe permite tomar consciência sobre o que, como e para quê está aprendendo, entender seus próprios processos cognitivos, e desenvolver a competência para monitorar tais 
processos. Vale ressaltar, ainda, que a criança com dificuldades ortográficas deve ser incentivada a discutir, visualizar, escutar, repetir, escrever e ler as correspondências grafofonêmicas trabalhadas $^{(27,29)}$.

A análise dos resultados mostrou também que a limitação dos itens lingüísticos a itens de transparência ortográfica, ou seja, à utilização, unicamente da regra de correspondência grafo-fonêmica independente do contexto, também permitiu diferenciar ou caracterizar GP em relação ao GC. Este procedimento foi de fácil e rápida aplicação e os resultados sugerem que o ditado de itens de transparência ortográfica pode ser aplicado com o objetivo de identificar problemas com relação ao aprendizado e desenvolvimento ortográfico e, também, permitem verificar a capacidade de percepção do erro, facilitando sua correção.

Estudos que promovam a indicação de que erros dessa natureza possam ser preditores de alterações ortográficas mais graves ou de inabilidades de leitura devem ser realizados.

A avaliação isolada da regra ortográfica de correspondência direta e independente do contexto pôde fornecer informações importantes sobre crianças com Transtorno Específico de Leitura, na medida em que mostrou que elas apresentaram pior desempenho que os escolares sem queixas ou transtornos, no uso e conhecimento da regra ortográfica elementar; de fundamental importância para o aprendizado do princípio alfabético. Esta regra deveria ser a primeira a ser dominada, dependente que é da capacidade de aprendizagem da criança que, provavelmente apresentará, subseqüentemente, outras dificuldades no uso das demais regras ortográficas.

Não foram encontrados, na literatura consultada, trabalhos que, semelhantemente a este, tenham avaliado isoladamente o domínio de uma única regra ortográfica. Entretanto, algumas pesquisas que também utilizaram procedimentos de avaliação do aprendizado ortográfico em seus experimentos, dão suporte a este estudo quando se observam seus resultados ${ }^{(1-4,6,8-9,12-13)}$.

Diante desses achados pode-se inferir que, comparadas às crianças do GC, as crianças do GP deste estudo, ainda, não desenvolveram todas as capacidades necessárias para o pleno e adequado aprendizado dos princípios do sistema alfabético, pois apresentaram dificuldades em escrever e analisar palavras e pseudopalavras sob ditado. Por outro lado, se considerarmos seus acertos, suas tentativas de meta-analisar seus erros, a evidente diminuição da quantidade de erros ao longo das séries avaliadas podemos pensar em suas potenciais capacidades de aprendizado e nos benefícios que podem lhes trazer a utilização de programas de intervenção fonoaudiológica e educacionais adequados e efetivos.

\section{CONCLUSÕES}

Por meio desta pesquisa, que teve como objetivos caracterizar o desempenho de um grupo de escolares com Transtorno Específico de Leitura (GP), ao escrever e explicar o uso da regra de correspondência grafo-fonêmica independente do contexto, na comparação com o GC, pode-se concluir que esses escolares:

- produziram mais erros em todas as combinações de série e item lingüístico, demonstrando dificuldade em codificar fonemas em grafemas principalmente ao escrever as pseudopalavras.

- diminuíram a quantidade de erros produzidos ao longo das séries.

- apresentaram menor pontuação da justificativa A em todas as combinações de série e tipo de item lingüístico mostrando maior dificuldade em escrever corretamente e analisar os itens lingüísticos escritos e reconhecer as escritas corretas.

- pontuaram mais a justificativa do tipo B, mostrando a possibilidade de reconhecimento do erro. Entretanto, identificaram-no apenas nas palavras de alta freqüência, evidenciando o efeito da familiaridade com a palavra sobre esse reconhecimento.

\begin{abstract}
Purpose: To investigate how children with dyslexia use the phonographemic correspondence rule in their writing regardless of context and how they identify and analyze their writing mistakes according to the variables: frequency of occurrence of the linguistic item and school grade. Methods: The writing errors observed on a task of dictation of high- and low-frequency words and pseudowords were analyzes and compared. Fifty-six students from $1^{\text {st }}$ to $4^{\text {th }}$ grades of private elementary schools were evaluated: 28 with dyslexia (research group), and 28 without writing complaints or deficits (comparison group), paired by age, gender and grade. The reasons for right and wrong answers were taped and compared. Results: The statistic analysis showed that students with dyslexia performed worse than the comparison group. Moreover, there was a decrease in the number of errors with the progression of schooling, especially in high frequency words. Students with dyslexia showed more difficulty to analyze the linguistic items and recognize their correct writing. Conclusion: Children with dyslexia had more difficulties in writing and analyzing linguistic items of transparent orthography. The effect of lexical frequency facilitated error identification. The occurrence of errors decreased with schooling progression and varied according to linguistic item.
\end{abstract}

Keywords: Dyslexia; Handwriting; Evaluation; Child language; Learning 


\section{REFERÊNCIAS}

1. Morais AG. Ortografia: ensinar e aprender. São Paulo: Ática; 1998. A norma ortográfica do português: o que o aluno pode compreender? O que ele precisa memorizar? p. 27-49.

2. Pinheiro AM. Leitura e escrita: uma abordagem cognitiva. Campinas: Editorial Psy; 1994. Resultados do teste de escrita; p. 167-186.

3. Rego LL, Buarque LL. Consciência sintática, consciência fonológica e aquisição de regras ortográficas. Psicol Reflex Crít. 1997;10(2):199217.

4. Zorzi JL. Aprender a escrever - a apropriação do sistema ortográfico. Porto Alegre: Artmed; 1998.

5. Monteiro DC, Nordi C, Silva CRG, Doricci GP, Marrara JL. Que tipos de erros ortográficos ainda existem na $5^{\text {a }}$ série do ensino fundamental? Fono Atual. 2004;29:40-49.

6. Ávila CRB, Ramos CS, Frigerio MC, Lucas S. Análise da escrita de escolares de $4^{a}$ série fundamental das redes pública e particular. Rev Soc Bras Fonoaudiol. 2001;1:23-8.

7. Guimarães SRK. O aperfeiçoamento da concepção alfabética de escrita: relação entre consciência fonológica e representações ortográficas. In: Maluf MR. Metalinguagem e aquisição da escrita. São Paulo: Casa do Psicólogo; 2003. p. 149-84.

8. Guimarães SR. Dificuldades no desenvolvimento da lectoescrita: o papel das habilidades metalingüísticas. Psicol Teor Pesqui. 2003;19(1):3345.

9. Angelelli P, Judica A, Spinelli D, Zoccolotti P, Luzzatti C. Characteristics of writing disorders in Italian dyslexic children. Cogn Behav Neurol. 2004;17(1):18-31.

10. Meireles ES, Correa J. Regras contextuais e morfossintáticas na aquisição da ortografia da língua portuguesa por criança. Psicol Teor Pesqui. 2005;21(1):77-84.

11. Meireles E, Correa J. A relação da tarefa de erro intencional com o desempenho ortográfico da criança considerados os aspectos morfossintáticos e contextuais da língua portuguesa. Estud Psicol (Natal). 2006;11(1):35-43.

12. Queiroga BA, Lins MB, Pereira MA. Conhecimento morfossintático e ortografia em crianças do ensino fundamental. Psicol Teor Pesqui. 2006;22(1):95-9.

13. Paula GR, Mota HB, Keske-Soares M. A terapia em consciência fonológica no processo de alfabetização. Pró-Fono. 2005;17(2):17584.

14. Pedras CT, Geraldo T, Crenitte PA. Consciência fonológica em crianças de escola pública e particular. Rev Soc Bras Fonoaudiol. 2006;11(2):120-9.
15. Britto DB, Castro CD, Gouvêa FG, Silveira OS. A importância da consciência fonológica no processo de aquisição e desenvolvimento da linguagem escrita. Rev Soc Bras Fonoaudiol. 2006;11(3):142-50.

16. Cárnio MS, Stivanin L, Vieira MP, Amaro L, Martins VO, Carvalho E, et al. Habilidades de consciência fonológica e letramento em crianças de ensino fundamental. Rev Soc Bras Fonoaudiol. 2006;11(4):231-42.

17. Capellini SA, Padula NA, Ciasca SM. Desempenho de escolares com distúrbio específico de leitura em programa de remediação. Pró-Fono. 2004;16(3):261-74.

18. Cárnio MS, Santos D. Evolução da consciência fonológica em alunos de ensino fundamental. Pró-Fono. 2005;17(2):195-200.

19. Gindri G, Keske-Soares M, Mota HB. Memória de trabalho, consciência fonológica e hipótese de escrita. Pró-Fono. 2007;19(3):313-22.

20. Gregg N, Gregg N, Mather N. School is fun at recess: informal analyses of written language for students with learning disabilities. J Learn Disabil. 2002;35(1):7-22.

21. Garcia VL, Campos DB, Padovani CR. Associação entre a avaliação de habilidades de consciência fonológica e de processamento auditivo em crianças com e sem distúrbio de aprendizagem. Fono Atual. 2005;8(31):4-11.

22. Caravolas M, Volín J. Phonological spelling errors among dyslexic children learning a transparent orthography: the case of Czech. Dyslexia. 2001;7(4):229-45.

23. Jardini RS, Souza PT. Alfabetização e reabilitação dos distúrbios de leitura/escrita por metodologia fono-vísuo-articulatória. Pró-Fono. 2006;18(1):69-78.

24. Salgado C, Capellini SA. Desempenho em leitura e escrita de escolares com transtornos fonológicos. Psicol Esc Educ. 2004;8(2):179-88.

25. DSM-IV. Manual diagnóstico e estatístico de transtornos mentais. Porto Alegre: Artmed; 1995.

26. Cunha NB, Santos AA. Relação entre a compreensão da leitura e a produção escrita em universitários. Psicol Reflex Crít. 2006;19(2):23745.

27. Barrera SD. Papel facilitador das habilidades metalingüísticas na aprendizagem da linguagem escrita. In: Maluf MR. Metalinguagem e aquisição da escrita. São Paulo: Casa do Psicólogo; 2003. p. 65-90.

28. Scliar-Cabral L. Princípios do sistema alfabético do português do Brasil. São Paulo: Contexto; 2003. Princípios aplicados à escrita; p.123-49.

29. Goulandris NK. Avaliação das habilidades de leitura e ortografia. In: Snowling M, Stackhouse J. Dislexia, fala e linguagem. Porto Alegre: Artmed; 2004. p. 91-120. 